\title{
Lã: Características e fatores de produção
}

\author{
Amarilho-Silveira, F. ${ }^{\circledR}$; Brondani, W.C. ${ }^{2}$ e Lemes, J.S. ${ }^{3}$
}

'SAFRA Empreendimentos. Brasil.

2Universidade Federal de Santa Maria. CESNORS. Brasil.

${ }^{3}$ Universidade Federal de Pelotas. Faculdade de Agronomia Eliseu Maciel. Brasil.

\section{PALAVRAS CHAVE ADICIONAIS}

Ovino.

Suarda.

Sustentável.

Velo.

\section{ADDITIONAL KEYWORDS}

Sheep.

Yolk.

Sustainable.

Fleece.

\section{INFORMACIÓN}

Cronología del artículo.

Recibido/Received: 3.3.2015

Aceptado/Accepted: 15.7.2015

On-line: 16.9.2015

Correspondencia a los autores/Contact e-mail:

amarill@@zootecnista.com.br

\section{RESUMO}

A lã possui propriedades naturais e aptidões particulares que há intitula como a rainha das fibras. Suas propriedades são apreciadas pela indústria e são limitantes ainda no animal, pois as mesmas prezam por manter a integridade de todo ressorte de fibras do velo. A lã é oriunda dos folículos secundário, quais começam a se formar ainda no útero, onde o processo inicia-se dos 80-90 e conclui-se aos 120-130 dias de gestação, e maturam ao longo de um ano de vida. Ela é envolvida pela cutícula, sua estrutura principal é o córtex e quando presente, característica indesejável, de medulação. A lã passa por um processo de revalorização demandado pela reformulação de hábitos, em que considerar produtos de qualidade, quais os seus impactos no ambiente sejam menores possível, é indispensável para uma produção sustentável.

\section{Wool: characteristics and factors of production}

\section{SUMMARY}

The wool has natural properties and special skills there are called as the Queen of fibers. Its properties are appreciated by industry and are still limiting the animal, because the same values by maintaining the integrity of all resort fleece fibers. The wool is from the secondary follicles, which begin to form in the uterus, where the process starts from 80-90 and concluded to 120-130 days of gestation and mature over a year of life. She is surrounded by the cuticle, its main structure is the cortex and when present, undesirable feature of medullation. Wool goes through a process of revaluation respondent by reformulation of habits, in which consider quality products, what are the impacts on the environment are less than possible, is indispensable for a sustainable production.

\section{INTRODUÇÃO}

Na década de 80-90 houve uma redução na produção mundial de lã, na ordem de $40 \%$, passando de 2 para 1,2 milhões de toneladas (Gea, 2007). A partir da década de 80 fatores relacionados ao mercado internacional acarretaram no declive da produção laneira. Segundo Viana (2008), entre os motivos que culminaram a crise está o grande estoque de lã da Austrália, principal produtor mundial, que criou um mecanismo de proteção comercial baseado em grandes compras e vendas de lã com o intuito de regular o preço. Porém, uma decisão única de desafiar os compradores a pagarem preços mais altos pela lã, fez com que os consumidores contestassem e deixassem de comprar. Com isso, a Austrália estocou o produto a espera de uma reação do mercado, fato que não aconteceu (Nocchi, 2001).

Nesse período também ocorreu o avanço tecnológico do setor têxtil, o que contribuiu para que fibra sintética ganhasse espaço no mercado, com preços altamente competitivos se comparados aos da lã (Silveira, 2005). Além disso, alguns acontecimentos ao longo da década de 90 também foram relevantes para esta crise. Citam-se o colapso na União Soviética (URSS), as crises da Europa Ocidental e Japão e a crise econômica na China e Ásia. Estes episódios colaboraram para a diminuição da demanda internacional de lã, o que justifica em partes, o aumento dos estoques na Austrália (Nocchi, 2001).

Como consequência dos baixos preços para as lãs de média micronagem, a valorização da carne ovina, a falta de diferenciação entre lãs médias e grossas, e uma demanda generalizada a nível mundial por lãs finas (19,5 micras e mais finas). Os rebanhos especializados na produção de lã diminuíram e muitos remanescentes estão sendo sujados (cruzados) com raças de carne, perdendo o peso de velo e qualidade de fibra (Gea, 2007). 
Em 2013 no Congresso Mundial Iwto, em Biella, Itália, Paul Swan coordenador do trabalho de bem-estar que esta realizando a Iwto, prospectou que até 2023 o consumo mundial de lã cairá em torno de $1 \%$ entre a produção de todas as fibras (em que atualmente ocupa $1,5 \%$ do consumo). Assim as vestimentas mais formais vão dar espaço para as de estilo mais casual (Martincorena, 2013). Logo assim a estimativa da seguinte safra era de um incremento de 1,7\%, projetando 1.102 milhões de quilos, porém com uma estagnação ou diminuição nos preços pagos (Bottaro, 2013).

O jornal Uruguaio El Pais noticiou no dia 28 de setembro de 2013 um aumento nas compras de lã Uruguaia por parte da China, devido uma queda na produção Australiana, devido a uma seca no Sul do pais (principal região produtora), que assinalaram reduções de 1,4\% para safra 2013/2014 (El Pais, 2013). Nesse contexto o principal comprador de lã a nível mundial é a China, que incrementou suas compras devido a uma prospecção de melhora na economia dos Estados Unidos e Europa, mercados compradores de produtos oriundos da lã (Bottaro, 2013).

Na safra de 2014/2015 a Austrália estimou uma produção 328 milhões de kg de lã em base suja, sendo $3,7 \%$ menor que a produção da safra anterior. Fato que se deu devido o aumento do abate de ovelhas adultas e cordeiros. Logo assim considerando o menor nível de produção nos últimos 90 anos. Então temos que na safra de 2012/2013 houve uma produção de lã em base suja com efetivos de 352 milhões de $\mathrm{kg}$, na de 2013/2014 foram 341 milhões de $\mathrm{kg}$ e a estimativa de produção de 2014/2015 foi de 328 milhões de kg. Outro fato importante considerando a volatilidade do mercado laneiro é a valorização do dólar americano, assim aumentando a competitividade de outros exportadores de lã (Bottaro, 2014). A mesma autora ressalta que durante setembro de 2014, a pesar de que em moeda local australiana o indicador tem-se mantido estável (AU \$ 1023 centavos por kg de lã em base limpa), em um marco de fortalecimento do dólar americano, o indicador tem diminuído quando traduzimos para esta moeda, ficando em US\$901 centavos por kg de lã em base limpa. A pesar de a Austrália ter diminuído suas exportações em 5,7\%, o valor das mesma só refletiu em $0,6 \%$ para a safra fechada em junho $(2013 / 2014)$.

Algumas perspectivas das econômicas, descrito por Bottaro (2014):

- O Fundo Monetário Internacional prevê uma taxa de crescimento $3 \%$ para 2015. Em que a economia americana se expande a uma taxa moderada e os indicadores do mercado laboral, dos gastos das famílias, das inversões que realizam empresas, começam a dar sinais de recuperação. A reserva Federal dos Estados Unidos emitiu alguns anúncios que tenham impulsionado ao fortalecimento do dólar a nível global.

- A atividade do setor privado na zona do EURO aponta um novo declive do crescimento. Os novos pedidos no setor manufaturado estão devagar e as expectativas de atividade comercial para o próximo ano vão voltar a premissas no setor de serviços, levadas a baixa por uma caída da con- fiança na Alemanha. Além disso, a preocupação devido a crise na Ucrânia, as conseguintes sansões a Rússia e a inquietude causada pela conjuntura econômica geral da zona do EURO parecem estar repercutindo cada vez mais na economia da zona da moeda única.

- A análise da economia do principal comprador de lã a nível mundial se baseia em que o Fundo Monetário projeta uma taxa de crescimento do PIB de $7,1 \%$ para 2015

- $\quad$ Estima-se que a produção da fibra de maior competitividade com a lã, o algodão, diminua pela terceira safra consecutiva, a pesar de que a área semeada aumentou em $4 \%$, impulsionado pelos Estados Unidos e Índia. Pelo contrário, China é um dos países que diminuirá sua área semeada.

- O objetivo desta revisão é abordar alguns fatores envolvidos nas características e na produção de lã, uma vez que, atualmente, os materiais encontrados são reproduções de publicações muito antigas.

\section{Propriedades dA LÃ}

A lã é tanto isolante do frio como do calor, principalmente, devido sua capacidade higroscópica, qual faz com que as mudanças no conteúdo de água da fibra de lã liberem ou absorvam calor como em nenhuma outra fibra. Assim quando absorve umidade, a lã libera calor e, ao perder, absorve calor. Portanto, ela absorve vapor de água do corpo ou do ar, formando uma interfase de ar seco, atuando como isolante térmico (Vieira, 1967; Gea, 2007; Osório et al., 2014). Essa característica lhe permite absorver até 30\% (Sul, 1987; Iwto, 2013), $40 \%$ (Vieira, 1967) ou 50\% (Minola e Goyenechea, 1975) da umidade do ar sem apresentar-se molhada, com isso considera-se ela também com uma característica saudável, porém em condições normais, o índice de higroscopicidade é de 16 a $18 \%$, devido à afinidade da queratina com a água (Vieira, 1967; McGregor, 2012; Osório et al., 2014). Em vista que a evaporação da transpiração é o melhor dispositivo para o esfriamento do corpo e ao ser absorvida pelas células cuticulares da lã, se mantem uma temperatura corporal uniforme (Iwto, 2013). Em contrapartida ela é repelente à água, devido à disposição, da base para a ponta, das suas células escamosas que recobrem sua superfície, fazendo circular os líquidos, dificultando a penetração de água (Gea, 2007).

McGregor (2012) revisando alguns trabalhos mostra que retenção de água tem efeitos importantes a se considerar, que vai influenciar nas suas propriedades como a variação no seu diâmetro. Quando a lã absorve água ela incha, sendo este inteiramente radial com pouco aumento no comprimento, porém tendo sua área transversal também aumentada cerca de 30\% com o aumento da umidade relativa de 0 a $100 \%$. O aumento do conteúdo de água na fibra de lã reduz a força e a rigidez.

Silveira et al. (2014a), em congresso de iniciação cientifica, apresentaram dados referente a capacidade de retenção de água da lã. Em que amostras de lã das regiões da espádua, do costilhar e da coxa foram submergidas em $\mathrm{H}_{2} \mathrm{O}$ por cinco e quinze minutos, onde 
indiferente do tempo de exposição e da região amostrada, a lã teve a capacidade de reter, em média, $45 \%$ da água a ela exposta. Os autores atribuíram importância nos reSultados como sendo uma fonte atualizada de uma predição, ainda longe da realidade, do quanto essa característica promove proteção ao animal frente a intempéries (ex. altos índices pluviométricos).

Outra característica importante é o fato da lã ser um elemento não inflamável. O contato com o fogo forma um botão carbonoso. Esta resistência ao fogo é um dos maiores atributos para sua utilização na prática, um exemplo é a sua utilização para forrar os acentos de aviões. O seu poder higroscópico impede a eletricidade estática. Devido à formação de uma interfase ar-fibra, consegue absorver ruídos, absorvendo de $40 \%$ de sons com frequência baixa e 98 \% de frequência alta (Vieira, 1967). Estudos recentes atestam que a lã também ajuda a proteger a pele contra raios ultravioletas, quando comparada a outras fibras usadas para o vestuário. Ela tem um fator natural de proteção contra os raios ultravioletas de 30 a $70 \%$ dos casos (Iwto, 2013). A umidade normal que toda a lã possui, ao diminuir a eletricidade estática repele o pó, o ar e a terra do ambiente (Gea, 2007).

A lã é naturalmente elástica, pode ser retorcida e estirada e vai retornar a sua forma normal mais do que qualquer outra fibra. Esta propriedade, no âmbito da sua utilização se traduz na liberdade de movimentos, que caracterizam as roupas fabricadas desta matéria prima (Gea, 2007). A fibra de lã pode estirar-se até mais de $50 \%$ de seu comprimento original. Há uma forte relação entre o comprimento da fibra sem estirar (longitude relativa) e estirada até o desaparecimento total das ondulações (longitude absoluta). Quando as fibras se unem entre si formam um verdadeiro ressorte linear que não só lhe permite esticar-se e recuperar sua forma original, propriedade conhecida como elasticidade ou resiliência (McGregor, 2012).

A alta capacidade de estiramento é muito valorizada nos processos de industrialização tais como cardado, penteado e fiado, pois as fibras sofrem importantes tensões, e uma baixa capacidade de estiramento provoca rupturas e desperdícios (Osório et al., 2014), diminuindo a produtividade. Essa alta capacidade de elasticidade é muito valorizada por confeccionistas e usuários de vestimentas e artigos de decoração como tapetes, já que as mesmas resistem a deformações pelo uso (Iwto, 2013).

Fibras finas, por exemplo, tornam possível a fabricação de fios mais finos, com uma maior flexibilidade e suavidade, porém com menor resistência ao desgaste por atrito, entretanto com um maior poder isolante (McGregor, 2012). Essas fibras mais finas resistem mais quando comprimidas, além do mais o rendimento e a velocidade de processamento são otimizados quando mais fina for à fibra (Barzola, 2009).

A lã além de características têxteis possui finalidades medicinais, como a utilização de lipídeos internos da lã, que possuem um alto conteúdo de ceramidas, que são extratos naturais com uma composição similiar à do extrato córneo humano, que são usadas em produtos para tratamento e cuidado da pele. Estes lipídeos formulados como lipossomos reforçam o efeito protetor e melhora a hidratação da pele sadia, acelerando a reparação da função protetora da pele lesionada (CSIC BIO022, 2008; CSIC BIO023, 2008).

\section{ATIVIDADE FOLICULAR}

A pele do ovino está constituída por dois tipos de tecidos diferentes, uma capa externa delgada, chamada de epiderme e por de baixo desta outra mais grossa e complexa conhecida por derme ou córion, formada por tecido conjuntivo que contém abundantes fibras de colágeno. Na derme, por sua vez, se distinguem em duas zonas bem diferenciadas, sendo uma superior chamada de papilar, prevista de numerosos vasos e fibrilas nervosas, que cumprem uma importante função na regulação da temperatura corporal e outra chamada reticular, formada por um tecido com fibras de colágenos (Osório et al., 2014).

A lã passível de ser manufaturada esta constituída por milhares de fibras, produzidas em diferentes tipos de invaginações da epiderme, conhecidas como folículos. Basicamente se distinguem em dois tipos de folículos, os primários e os secundários (Vieira, 1967). Os folículos primários dão origem aos pelos, que não têm crescimento continuo e caem periodicamente, mas podem dar origem também a fibras que, ao contrário, crescem indefinidamente, como fibras heterotipicas e kemps (Osório e Osório, 2004). Este folículo começa seu crescimento ao redor dos 45-60 dias de vida fetal, chegando ao estado de papila, potencialmente funcional aos 70-75 dias, aproximadamente. Antes de alcançar o dobro de seu tamanho começa a achatar-se na base e as células da derme começam a se concentrar na mesma. Ao lado do folículo imaturo começa a se formar a glândula sebácea, e ao final deste estagio, a seu lado se forma uma glândula sudorípara binoculada. E por ultimo se forma sobre o mesmo lado onde estão formadas as glândulas sebáceas e sudoríparas, o musculo eretor Pili. Todo o processo se conclui em volta dos 90 dias (Gea, 2007).

Os folículos secundários apresentam certas diferenças a respeito dos primários. O mais importante é que a maioria destes formam novos folículos a partir dos originais. O número desses folículos é variável, sendo influenciado por fatores hereditários relacionados com a raça, com o aperfeiçoamento desta, com a individualidade e com a nutrição recebida do feto através da ovelha. Em média oscila entre 5 a 30 folículos secundários entorno de cada tríade de folículos primários (como é dimensionado em grupo de três) e esse número é determinado no momento do nascimento do cordeiro, e por sua vez determinará a quantidade de lã que o ovino adulto poderá produzir e a pureza dela, representada pela maior ou menor porcentagem de pelos em relação à lã pura (Osório e Osório, 2004).

A formação e a maturação destes dependem em grande parte da nutrição, onde ela deve ser de qualidade, principalmente durante o último terço da gestação, lactação e primeiros meses de vida do cordeiro, o contrário se afetará a futura produção de lã do animal durante toda sua vida (Khan et al., 2012). A formação começa aos 80-90 dias de gestação, aos 120-130 começa e chega ao máximo de sua maturação e se finaliza 
aproximadamente a um ano de vida (Minola e Elissondo, 1990), porém se houver uma restrição pós-natal no fornecimento de nutrientes não vai ocorrer à redução no número de folículos, mas, permanentemente, pode prejudicar a capacidade de alguns folículos em produzir fibras, assim podendo retardar a maturação destes por até 6 a 12 meses (Khan et al., 2012). A base biológica de uma redução permanente da capacidade dos folículos em produzir fibras não foi elucidado, mas pode ser uma redução no tamanho da população de células do bulbo do folículo. Os estudos de Schinckel e Short (2001) com ovelhas Merino ilustram a magnitude dos efeitos da restrição pré e pós-natal de nutrientes na produção de lã de ovinos adultos. As ovelhas foram bem ou mal alimentadas durante a gestação e seus cordeiros foram tratados da mesma forma durante as primeiras 16 semanas de vida pós-natal. Os ovinos que foram criados em um plano nutricional pobre, produziram $20 \%$ menos lã na maturidade do que aqueles criados sobre um melhor plano nutricional.

As ramificações destes folículos aparecem, quando uma vez formada a glândula sebácea rudimentar que os acompanha. A formação do canal piloso é um pouco mais tardia, e este não se multiplica de baixo das capas mais exteriores da epiderme, como ocorre com os primários (Osório et al., 2014).

Os folículos secundários derivados apresentam os mesmos estágios de desenvolvimento que os originais com a exceção destes, não são formados pela epiderme e não apresentam glândulas sudoríparas. Sua glândula sebácea se desenvolve mais tardiamente, porém o canal piloso por onde passa a fibra é similar ao que se desenvolve no folículo original (Gea, 2007).

\section{ProdutOS dOS FOLÍCULOS}

A lã é produzida devido ao crescimento acelerado das células papilares de Malpighi (capa papilar), assim a capa superior da pele não cede, logo acorrendo à multiplicação dessas células epidérmicas, quais são empurradas junto com a papila germinativa até o tecido subcutâneo (derme). Esse amontoamento é cada vez maior e as células mais antigas não são alcançadas pelo líquido alimentício e morrem, formando uma unha córnea queratinizada e terminada em ponta, que logo é expulsa para fora, assim formando a fibra, e vão crescendo conforme outras novas células morrem e se acumulam. Esse processo inicial conclui-se aproximadamente aos 100 dias de vida fetal, logo assim quando o crescimento passa para o nível da glândula sebácea, se considera que o folículo está maduro (Gea, 2007; Osório et al., 2014).

Ela é formada por um composto proteico, denominado queratina, onde as proteínas fibrosas estão incluídas dentro do subgrupo das queratinas, caracterizadas por ter um alto conteúdo de Sulfuro. A macromolécula de queratina possui uma grande cadeia de aminoácidos e um dos mais importantes é a cistina, qual define muitas das principais propriedades em relação ao comportamento químico da lã (Osório e Osório, 2004). Ela apresenta 19 aminoácidos, a saber, a glicina, leucina, alanina, isoleucina, fenilalanina, triptofano, valina, prolina, serina, treonina, tirosina, metionina, cistina, cisteína, arginina, lisina, histidina, ácido aspártico e ácido glutâmico (Vílchez Maldonado, 2005).

A cistina confere grande rigidez e estabilidade térmica há queratina, logo assim criando uma forte e rígida hélice qual molda a matriz fibrosa da fibra através das pontes dissufuro (S-S) reticuladas formados a partir do alinhamento da cisteína, em que as moléculas de queratinas helicoidais torcem juntas, formando uma insolúvel e alongado vertentes como filamentos intermediários (Tung e Daoud, 2009).

Comparando-se a fórmula química da lã com a do algodão e da seda que são as seguintes: Algodão-C6H10O5; Seda-C24H38O8N8 e a Lã-C42H157O15N5S15. Verifica-se que a diferença está no elemento Nitrogênio $(\mathrm{N})$ presente nas fibras de origem animal e na presença do enxofre (S) que só se verifica na lã. A composição química da lã é a seguinte: Carbono 52\%, Oxigênio 22 a 25\%, Nitrogênio 16 a $17 \%$, Hidrogênio $7 \%$, Enxofre 3 a $4 \%$, cálcio 0,09 a $0,12 \%$, fósforo 0,017 a $0,023 \%$ e uma quantidade indefinida de sódio (Vieira, 1967; McGregor, 2012).

$\mathrm{Na}$ queratina de fibras de origem animal foram encontrados, provavelmente uma monocamada, de ácidos graxos na superfície da fibra. Esta camada é responsável pela natureza hidrofóbica das fibras, assim afetando o comportamento de translocação, acabamento e performance ao tingimento, e utilização final como na indústria estética como identificador de propriedades de suavidade, encolhimento ao lavar, etc. (McGregor, 2012).

A fibra de lã é um cilindro córneo composto por duas capas de células. A capa exterior, de aparência escamosa, formada por células cuticulares, recebe o nome de cutícula, e a interna, uma sucessão de medulas ou células corticais alargadas, denominando de córtex. Ela é formada no interior do folículo piloso, onde o líquido linfático exsudado pelos vasos sanguíneos através da base do folículo contribui para constituição das células, a princípio granuladas e posteriormente com núcleo, as quais se tornam alongadas, vindo a formar a parte cortical da fibra, enquanto células arredondadas formam a capa medular (Osório et al., 2014).

A descrição dos constituintes da fibra da lã segundo Vieira (1967), Minola e Elissondo (1990), Osório e Osório (2004), Gea (2007), Naebe (2009), McGregor (2012), Iwto (2013), e Osório et al. (2014):

- As células cuticulares são constituídas de células que sofrem modificações, perdendo a sua forma e tornando-se achatadas conferindo aparência escamosa. São duras, poliédrica, anucleadas, com bordas ligeiramente onduladas. Sua face externa é convexa, apresentando numerosos e diminutos poros. O seu crescimento é decorrente da carga genética e aporte nutricional. Estas células, independentemente do tamanho que tenha a fibra, são de tamanho similar, portanto, em lãs finas, uma só é suficiente para envolver a fibra, tanto que lãs grossas são necessárias mais de uma para ela.

- Histologicamente, na capa cuticular, se distinguem três zonas: epicutícula, exocutícula e a endocutícula. A epicutícula é constituída de queratina, assim 
tendo característica de resistência frente à ação de produtos químicos, desempenhando um papel chave na proteção da fibra. Ela é levantada em forma de bolhas quando imersa em soluções de cloro. A sua superfície é recoberta por uma camada extremamente fina quimicamente delimitada por uma, provavelmente monocamada, de acido graxo de estrutura química incomum. Esta monocamada é responsável pela repelência à água, sendo sua quantidade diferente para as fibras de cashmere, mohair e de alpaca.

- As células cuticulares estão unidas por cemento intercelular e sua disposição em forma sobreposta, com as bordas celulares superiores salientes, lhe confere a aparência de escamas. Ela tem um brilho característico, que está relacionado com o diâmetro da fibra e com a quantidade de células que são necessárias para envolvê-la. Em caso que seja uma só célula cuticular a envolver a fibra, o brilho é mais opaco quando comparado as que necessitam de mais de uma para recobrira-la totalmente, ou seja, fibras mais grossas brilham mais do que fibras mais fina, devido a uma maior superfície de reflexão das bordas livres das células. Assim como o cashmere e mohair necessitam de 1 a 2 células para envolver a fibra, fibras grossas necessitam de 8 a 10 células.

- A cutícula constitui 10 a $20 \%$ do peso de uma fibra, com função protetora. Os outros 80 a $90 \%$ são constituídos pelas células corticais. Uma fibra de lã de 20 micras de Merino Australiano apresenta células cuticulares adjacentes às células paracorticais mais grossas, mais compridas e mais sobrepostas, mas com menor altura e ângulo da borda mais agudo em comparação as células adjacentes as ortocorticais. Assim Wildman (1954) apud McGregor (2012), descreveu com um diagrama de frequência que ilustra a distribuição das escamas cuticulares /100 $\mu \mathrm{m}$ para cashmere comercial e lã de Merino de $18 \mu \mathrm{m}$. As duas amostras de cashmere variou de 4 a 10 escamas / $100 \mu \mathrm{m}$ e 4,5 a 9,5/100 $\mu \mathrm{m}$, respectivamente. A lã de Merino variou 5,5 a 11 escamas $/ 100 \mu \mathrm{m}$ com valor médio de 8,5 a 9 escamas $/ 100 \mu \mathrm{m}$. Logo assim há uma distinção nos valores encontrados devido à forma cuticular traduzida em escama, onde o cashmere se apresenta quadrada e a lã em tiras. Assim essas diferenças são em resposta ao numero de cutículas necessário para recobrir uma fibra, e também pelo cashmere apresentar mais células ortocorticais. Portanto esses dados traz o entendimento da associação da diminuição da rigidez de flexão de fibras de cashmere em comparação as de lã Merino. Outro dado de interesse de distinção também é o de Wortmann et al, (1988) apud McGregor (2012), qual diferencia as fibras de mohair, cashmere, camelo, alpaca, yaque e uma ampla variedade de lã pela altura da cutícula, em que as lãs apresentam uma altura média de 0,7 a 0,9 $\mu \mathrm{m}$, enquanto valores para outras fibras são em torno de uma média de $0,3 \mu \mathrm{m}$.

- As células corticais são células alargadas, do tipo fusiforme, dispostas em sentido longitudinal e formam o verdadeiro nervo da fibra. Suas medidas são variáveis em ambos os sentidos, segundo a força a que estão sendo submetidas. Em cortes transversos e mediante de microscópios de grande resolução, se observam conjuntos circulares, envoltos pela capa cuticular. Têm uma complexa constituição interna. Cada célula cortical está composta de uma série de fibrilas concêntricas, unidas por substâncias cementantes, que recebem o nome de macrofibrilas, microfibrilas e protofibrilas. Cada macrofibrila está constituída por uma serie de microfibrilas de $8 \ddot{\mathrm{A}}(\ddot{\mathrm{A}}=$ amstrong= milésima parte de 1 micra= milésima parte de 1 $\mathrm{mm}$ ) de diâmetro, que por sua vez estão formados por 11 protofibrilas de aproximadamente $2 \ddot{A}$ de diâmetro. As protofibrilas estão integradas por três corpos moleculares helicoidais, denominados de hélices alfa e estas estão formadas pela unidade básica das proteínas, os aminoácidos.

- As células corticais consistem em dois tipos principais, as células ortocorticais (65-68\%) e paracorticais (35-32\%), possuindo ligeiramente diferentes propriedades físicas e químicas. Há muitos anos foram consideradas, quando estão dispostas bilateralmente, como responsáveis pela formação das ondulações em fibras de lã fina. No entanto o conhecimento atual do crescimento celular a nível de folículo, fornece uma explicação diferente para a formação das ondulações. Hearle (2005) sintetizando trabalhos mais antigos que mostraram que as ondulações da fibra reSultam da contração diferencial das células ortocortical, que contém macrofibrilas enroladas de forma helicoidal, e as paracorticais, em que as microfibrilas são paralelas ao eixo da fibra. Então a formação se dá quando as ortocorticais tendem em aumentar seu comprimento e as paracorticais permanece constante. Se a fibra não é livre para girar, as ondulações desenvolvem, alternando com as cadeias esquerdas e direitas das hélices, como em fibras sintéticas de dupla composição, porém se a fibra é livre para girar, as ondulações desenvolvem com uma simples cadeia helicoidal. No entanto, algumas fibras de origem de animais exóticos têm poucas células paracorticais ou elas são distribuídas radialmente.

- O tamanho e diâmetro das células corticais são relacionados inversamente com o crescimento da lã, qual tem um declínio na atividade mitótica de células no folículo e redução da compressão celular longitudinal. Assim no inverno as células corticais são maiores.

- Fibras de origem animal podem ser consideradas um conjunto de células corticais e cutícula, unidas por uma célula chamada de complexo de membrana. Ela constitui pequena porcentagem do conteúdo da lã, mas tem grande importância, uma vez que controla ou influência as propriedades das fibras. Propriedades mecânicas como resistência a abrasão ou ao desgaste são de total dependência desta membrana, e porque ela é a única estrutura de constituição continua na fibra. A difusão de materiais corantes e outros reagentes de processamento químico, para dentro ou através da fibra é 
uma das funções desse complexo. A epicutícula é considerada um componente do complexo membrana.

- A camada mais interna da fibra de lã, terceira camada, denominada medula, pode aparecer ou não, pouco frequente em lãs finas ( $<35$ micras). Ela é formada por células superpostas de tamanho e forma irregulares, muitas vezes poligonais, apresentando estrutura semelhante ao favo de mel, contendo ainda ar, no seu interior. $\mathrm{O}$ aparecimento de medula na fibra de lã ocorre durante o processo de queratinização, podendo ocorrer quando as células, da camada cortical, perdem líquido e ficam cheias de ar, conservando ou não as membranas. No caso de rompimento das membranas, a medula aparece como um canal oco no centro da fibra. Essa medulação é uma característica indesejável, desvaloriza a lã, devido à presença de ar dentro da fibra, provocando refração a luz, produzindo dificuldades no processo de tingir, caracterizando as fibras meduladas como mais claras. Ao serem trabalhadas na indústria não absorvem as tintas e dão certa aspereza ao tecido, o que muito o deprecia.

- $\quad$ O contorno ou a elipticidade da fibra refere-se à relação entre os diâmetros transversais maiores e menores de uma fibra. Fibras de origem animal não são de secção transversal circular, mas elípticas. Estudos demonstraram uma maior elipticidade da maioria das fibras de animais exóticos quando comparada a lãs finas. Fibras meduladas tendem para a forma de rim, em secção transversal apresentam a maior elipticidade. $\mathrm{O}$ aumento da elipticidade pode reduzir a rigidez de flexão de fibras de origem animal.

Crescimento da fibra é marcadamente hormôniodependente, onde a manipulação experimental do status hormonal provoca grandes alterações na taxa de crescimento da lã. Os hormônios hipofisários, incluindo o hormônio estimulante da tireóide (TSH), hormônio adrenocortico-trófico (que atuam sobre as glândulas alvo) e hormônio do crescimento, exercem uma influência controladora sobre o crescimento de lã (Wallace, 2000). Uma vez extirpada a glândula pituitária, o crescimento para ou é interrompido, visto que a administração do hormônio estimulador da tireoide (TSH) pode restabelecer o crescimento da lã em ovinos hipofisectomisados e a administração de hormônio tireoidiano aumenta o crescimento da lã, devido a sua ação que incrementa um maior consumo voluntário de alimento e/ou reduz o tecido proteico acumulado e no peso corporal (Osório et al., 2014). O hormônio do crescimento estimula o crescimento de lã em ovelhas normais, por estimular a secreção de polipeptídios, conhecido como somatomedinas (Khan et al., 2012).

A lã grossa conhecida com o nome de lã de cachorro, que se observa na perna de muitos ovinos, é quase toda ela formada por pelos e fibras meduladas. Esse defeito além de ser transmissível por herança, logo aumentando sua incidência conforme a senescência (Osório e Osório, 2004; Khan et al., 2012).
Já o pelo é uma fibra grossa, de aproximadamente 50 micras ou maior, originado nos folículos primários. Apresenta o aspecto de um cilindro oco, previsto de um potente canal medular. Eles têm uma superfície lisa e suas escamas são apenas visíveis ou não existem. Suas propriedades físicas são totalmente diferentes da lã. São frequentes em raças de lãs medianas (Roney Marsh) e grossas (Lincoln e Crioulas), porém também podem ser encontrados em quase todas as raças conhecidas, tanto nas de lãs finas e de grande pureza racial como o Merino (Gea, 2007).

Os kemps ou birth coat, é um tipo de pelo rígido, curto e de cor branca, que se visualiza bem em cordeiros recém-nascidos até 3-4 meses de idade (Gea, 2007). Ao conjunto mais ou menos difuso destas fibras, cuja função principal é de proteger o neonato do frio durante as primeiras horas de vida (Vieira, 1967). Este tipo de elemento nasce nos folículos primários. Se um cordeiro nasce com muitos kemps, terá uma maior proteção contra as intemperes do ambiente, porém tem uma alta probabilidade de esse animal, no futuro, apresentar um velo de baixa qualidade (Osório et al., 2014). Estes são fortemente medulados, com uma superfície lisa, com crescimento descontinuo e com diâmetro de aproximadamente 80 micras (McGregor, 2012).

\section{VELO}

Pode-se definir velo, como sendo toda a lã do corpo do animal com exceção das regiões das patas, cabeça e barriga e com o crescimento aproximado de um ano. Ele composto por uma completa associação de distintos tipos de fibras, secreções glandulares, descamações epiteliais, impurezas naturais ou agregadas e água, cuja principal função é atuar como elemento termorregulador (Vieira, 1967). Sua estrutura está diretamente relacionada com o numero, distribuição e comportamento dos folículos, evento que se conhece como relação secundários / primários $(\mathrm{S} / \mathrm{P})$, sendo que quanto maior a relação S/P mais fina é a lã do velo (Gea, 2007).

Minola e Elissondo (1990), caracterizam por raça e idade a relação $\mathrm{S} / \mathrm{P}$, onde a raça Merino apresenta 20:1, Ideal 15:1, Corriedale 10:1, Romney Marsh 5:1 e Lincoln 4:1. Quando levando em consideração a idade como exemplo cordeiro da raça Merino, caracterizaram sua relação S/P é de 4:1 e se completa durante o primeiro ano de vida.

A suarda é a secreção das glândulas sebáceas e sudoríparas, sua principal função consiste em lubrificar a pele e a fibra, colocando-se numa função de proteção contra agentes externos. Sua maior concentração se encontra na região superior do velo. Em lãs finas a suarda é maior que em lãs grossas, devido à quantidade superior de folículos primários e secundários (Gea, 2007).

A suarda é composta por duas frações, a suintina e a cera. A suintina é secretada pelas glândulas sudoríparas dos folículos primários, é solúvel em água e esta composta em sua maior parte por sais de potássio de ácidos orgânicos e inorgânicos. A cera é produzida pelos dois tipos de folículos, é insolúvel em água e solúvel em solventes orgânicos (éter de petróleo). Seu principal componente é a lanolina. A cera quando se hidrolisa se decompõem em uma serie de ácidos 
orgânicos e álcoois, é rica em colesterol, utilizado na formação de pró-vitamina $\mathrm{D}$, testosterona e progesterona. A proporção de cera varia conforme a raça, animal e diferentes regiões do corpo. A região da paleta é a que tem maior quantidade de cera, depois na parte do quarto e por ultimo a região superior e inferior do pescoço (Minola e Elissondo, 1990).

O velo ideal é aquele que tem a cor branca pura, com mechas de bom tamanho, suave ao tato e protegido por grande quantidade de cera fluída. Uma das principais características que se deve ter em um velo é uma adequada arquitetura, esta permite uma rápida ventilação e secagem após molhado (Gea, 2007). Portanto suas mechas devem ser carnudas com pontas planas nas lãs finas e cilíndricas nas de maior diâmetro de fibra, separadas entre si, mas sem perder a densidade, com ondulações regulares e uniformes desde a ponta até a base da mecha como preconiza Iwto (2013).

Um velo inferior tem irregularidades na sua estrutura, com pouco caráter e/ou estilo indefinido, é áspero e pegajoso ao tato, devido à baixa qualidade de suas secreções, sua ventilação é pobre e a secagem é lenta. Sabe-se que quanto mais lenta é a secagem do velo, maior é a predisposição a diferentes patologias associadas com a cor, pela proliferação de bactéria e fungos cromógenos (que formam a cor). Por outro lado, como as mechas se apresentam desuniforme com irregularidades na arquitetura do velo, vulnerabiliza-o contra os efeitos ambientais (Osório et al., 2014).

Vieira (1967) estratifica o velo em estado bruto, tal como é retirada por ocasião da tosquia, contem cerca de $50 \%$ de outros elementos, conforme indicamos a seguir, variáveis com a classe e com as condições do meio, onde é criado o rebanho: Lã pura 30-80 \% (média de $51 \%$ ), suarda 5-30\% (média de $22 \%$ ), água 12-21\% (média de $17 \%$ ), matérias vegetais $0,5-5 \%$ (média de $4 \%$ ) e matérias terrosas 5-20\% (média de 6\%).

\section{FATORES QUE INFLUENCIAM A PRODUÇÃO DA LÃ}

Nas condições de produção ovina, na grande maioria dos casos, a criação a base de pastagens, tanto naturais como cultivadas, ostenta flutuações anuais e estacionais em quantidade e qualidade de forragem disponível, logo assim produzindo variações no diâmetro médio das fibras que compõem o velo (Sacchero et al., 2010). Há outros fatores tão o mais importante a se considerar na produção ovina. Fatores não genéticos como o estado fisiológico, a idade, efeito materno, comportamento reprodutivo, momento da esquila, estado sanitário e o clima, vão determinar o crescimento da lã, o diâmetro médio de fibras e a resistência à tração das mechas (Friends e Robards, 2005). Fatores Genéticos como sexo, raças e linhas genéticas dentro de raças (Cardellino, 1983).

A máxima produção de lã esta entre o segundo e terceiro ano de vida do animal e, a partir do terceiro ano diminui entre 2 e $4 \%$ ao ano (Sul, 1987). Assim, quando a base da finalidade produtiva é a lã ou quando esta representa um ingresso significativo em uma propriedade, deve-se evitar a permanência de animais velhos no rebanho. Como também, quando a seleção é realizada por peso de velo, em ovelhas ou animais de diferentes idades, há necessidade de utilizar fatores de correção, para que a potencialidade genética possa ser devidamente comparada (Osório, 1979).

Sacchero et al. (2010) ao avaliarem a resposta da idade dos animais em duas linhas genéticas (selecionados para diâmetros de lã superfina e não selecionados), a saber, ovelhas de segunda esquila (jovens), de terceira e quarta esquila (adultas) e de quinta e sexta esquila (velhas), encontram diferenças nas características de diâmetro somente na linha superfina, onde ovelhas velhas apresentaram maiores diâmetros médios, maiores diâmetros máximo e maiores diâmetros mínimos do ponto de diâmetro máximo até a base da mecha. Fato que se atribui pelo fato que animais mais velhos, quando comparados a animais mais jovens em programas de e melhoramento, são menos selecionados, logo assim melhor transparecendo as características adicionadas com o programa (Brown et al., 2002). Sacchero et al. (2011) encontraram diminuições do ponto de diâmetro mínimo referente a 0,6 micras quando comparados a ovelhas velhas.

Os machos produzem lãs mais grossas, assim como mechas mais compridas e pesadas que as fêmeas, porém a eficiência de produção de lã esta intimamente ligada ao peso corporal, independente do sexo. A maior produção de lã é de machos inteiros, portanto, está em função de seu maior tamanho corporal e peso vivo, que são produtos de uma adequada atividade testicular e um bom equilíbrio endócrino. Assim machos castrados (capões) produzem lã menos que inteiros e mais que fêmeas. Essa inferior produção pelas ovelhas são decorrentes a sucessões de mudanças fisiológicas, como gestação, lactação e até no desmame (Minola e Elissondo, 1990).

Efeito materno, em animais filhos de borregas ou nascidos como gêmeos produzem, ao chegar a idade adulta, entre 5 e $10 \%$ menos de lã que os filhos de ovelhas adultas e de partos simples. Essa diferença deve-se ao menor número de folículos secundários formados durante a gestação e a menor quantidade de leite que recebe os filhos de borregas e de partos múltiplos, o que influiria na maturação dos folículos secundários (Vieira, 1967). Logo, Thompson e Young (2002) relatam que a perda de peso das mães neste período normalmente se associa a menores valores de peso de velo limpo, diminuição da resistência à tração, inferioridade marcante no peso e sobrevivência de cordeiros ao nascer e a mudança permanente da população de folículos da pele do feto. Os mesmos autores relatam que ovelhas melhor alimentadas nos períodos de maior exigência produzirão descendência que irá produzir lã em maior quantidade e de melhor qualidade ao longo de suas vidas.

Tanto a gestação como a lactação apresenta um efeito negativo sobre a produção de lã em ovelhas. Normalmente, as falhadas produzem entre 4 e $12 \%$ mais de lã que as que gestaram um cordeiro, e estas por sua vez produzem de 4 a $12 \%$ mais de lã que as que gestaram gêmeos, dependendo do nível de alimentação no último terço da gestação (Khan et al., 2012). Por sua vez a lactação reduz o peso de velo em 5-8\% (Sul, 1987). Estima-se que o efeito total da gestação mais a lactação 
sejam de 10 a $14 \%$, na redução da produção de lã, em condições de uma boa alimentação e de 20 a $25 \%$, quando a alimentação é pobre (Gea, 2007). A gestação e a lactação diminuem a atividade folicular, podendo levar a um estrangulamento das fibras, ocasionando uma diminuição na resistência das mesmas (Osório e Osório, 2004).

Sacchero et al. (2011) trabalhando com ovelhas Merino em Rio Negro, Argentina, em diferentes estágios fisiológicos, encontram diminuições de 0,6 micras para o ponto de diâmetro máximo e do ponto de mínimo diâmetro ao longo da fibra, para ovelhas que gestaram e desmamaram cordeiros, contrapondo à ovelhas que não desmamaram. Os mesmos chegaram a reSultados de um aumento de $16 \%$ no diâmetro ao decorrer do primeiro estágio de crescimento $(\mu \mathrm{m} / \mathrm{mm})$ de fêmeas secas (que não estavam prenhes), comparando com ovelhas que desmamaram. Assim explicam que possivelmente há uma diferença na partição de nutrientes (mobilização de reservas) que realizam ovelhas prenhes contrapondo as ovelhas secas, aumentam seu consumo para a produção de leite e acabam relegando o engrossamento das fibras.

Sacchero et al. (2010) relatam a coincidência do ponto de menor diâmetro ao longo da fibra com épocas de baixa disponibilidade forrageira e de mudanças fisiológicas, como a gestação e lactação. Onde a redução do diâmetro alcançou valores de 10 pontos percentuais, ou seja, animais com diâmetro médio com 19,9 micras apresentaram o ponto de estrangulamento (ponto do diâmetro mínimo) com aproximadamente $17,8 \mathrm{mi}$ cras. Assim os mesmos autores concluem que o estado fisiológico (pré-parto) até o desmame é o período em que as ovelhas apresentaram menores diâmetros médios de fibra. Rauw et al. (2010) encontraram menores diâmetro de fibra para ovelhas prenhes quando comparadas a falhadas, e diâmetros inferiores para fêmeas que gestaram gêmeos. Fato interessante neste estudo foi que ovelhas com menores diâmetros apresentaram menores perdas de peso, e também foram as que apresentaram maiores taxas de parição. Lee et al. (2002) observaram uma correlação genética de 0,40 entre o diâmetro de fibra e ingestão de matéria orgânica digestível em condições de campo, e sugeriram que a seleção para lãs mais finas poderia acarretar numa menor exigência de ingestão.

Em 1989 já se falava em promover uma melhor condição nutricional com o atendimento de exigências adicionais, assim burlando a obrigatoriedade de que mudanças fisiológicas diminuírem o diâmetro da fibra (Williams e Butt, 1989). O NRC (2007) descreve as exigências para mantença uma ovelha qual necessita de $53 \%$ de nutrientes digestíveis totais (NDT) e $7 \%$ de proteína bruta (PB), para inicio da gestação $53 \%$ de NDT e $8 \%$ de PB, para fim de gestação $66 \%$ de NDT e $10 \%$ de PB, e inicio da lactação $66 \%$ de NDT e $15 \%$ de PB. Porém as diferenças no diâmetro das fibras devido a essas distintas transições fisiológicas se manifesta a partir do ultimo terço de gestação e não são permanentes já que se reduzem paulatinamente logo ao desmame até desaparecer, ao encontrar o ponto de equilíbrio entre as exigências e a demanda nutricional (Sacchero et al., 2011).
Apesar de antigas, algumas bibliografias focam mais na produção de lã, como carácter de principal produção (devidamente por se tratar de uma época que a lã era um produto rentável). Com isso descreve-se que o ARC (1980) e AFRC (1993) adotaram um valor de $130 \mathrm{KJ} /$ dia, para um crescimento médio de 5,5 g de lã por dia, o que significa um valor energético de 23,7 MJ / kg de lã. O NRC (1985), não refere à exigência de energia específica para crescimento de lã, mas parece que ela está englobada na exigência de mantença e crescimento.

Ovelhas com uma produção média de 3,0 kg de lã por ano, sendo que a lã contém $800 \mathrm{~g}$ de proteína por $\mathrm{kg}$, isto corresponde a $8,2 \mathrm{~g}$ de lã / dia ou 6,6 g de proteína $/$ dia $=6,6 / 0,30=22,0$ (AFRC, 1993).

A proteína bruta da lã (PLã) de ovelhas e machos adultos foi estimada em 6,8 g/dia, admitindo-se uma produção animal de $4 \mathrm{~kg}$ de lã. Para animais em crescimento a PLã $=3+(0,1 \times$ proteína retida na lã $)$, segundo o ARC (1980). O VPL (valor proteico líquido) dos alimentos foi estabelecido como 0,561 , baseado na digestibilidade real de 0,85 e no valor biológico de 0,66 citado pelo NRC (1985). Assim sendo, o esquema fatorial do NRC (1985) para determinar a estimativa da exigência proteica de ovinos com o rúmen desenvolvido será:

$\mathrm{PB}$ em g/dia $=(\mathrm{PMF}+\mathrm{PUE}+\mathrm{PG}+\mathrm{PLã}) \mathrm{VPL}$

- A PB g/dia é estimada pela soma das frações correspondentes à proteína metabólica fecal (PMF), proteína urinária endógena (PUE), proteína gasta nas perdas de pelo e secreção dérmica (PPD) usada para bovinos, proteína depositada no ganho de peso, no feto e excretada no leite (PG) e proteína utilizada para síntese de lã (PLã). A exigência líquida e transformada em exigência dietética por um fator de correção do valor proteico dos alimentos (VPL).

Onde:

$\mathrm{PMF}=$ está relacionada com a ingestão de matéria seca (MSI)

$\rightarrow 33,44 \mathrm{~g} / \mathrm{kg}$ MSI

PUE $=0,14675$ PV em kg +3,375 g/dia

A PG para crescimento e GPV em g/dia= GPV $(\mathrm{kg})$ $\times(268-29,4 \times \mathrm{VEG})$

$\mathrm{VEG}=($ valor energético do GPV $)$ em $\mathrm{Kcal}=(\mathrm{El}$ g Kcal/dia)/(GPV g/dia).

- A exigência para gestação de uma ovelha com uma cria é de 2,95 g/dia no início da gestação e nas quatro últimas semanas de gestação é de $16,75 \mathrm{~g} /$ dia, sendo os aumentos proporcionais aos números de crias. As exigências para ovelha em lactação baseiam-se nas produções de leite de 1,74 e 2,60 kg/dia, respectivamente, para ovelhas amamentando um a dois cordeiros e com teor de PB do leite de 47, $875 \mathrm{~g} / 1$.

Rauw (2008) propôs um modelo para estimar o consumo de pastagem em termos de unidades estimadas de energia consumida: 
EGII $=$ FII-B0 $-\mathrm{ei}=(\mathrm{b} 1 \times$ PVI 0,75$)+(\mathrm{b} 2 \times \Delta \mathrm{PVi})+(\mathrm{B} 3 \times$ Prodi $)$ Onde:

EGII = ingestão de pastagem estimada do indivíduo i; FII = consumo de ração real do indivíduo i;

PVI 0,75= Peso metabólico;

$\Delta \mathrm{PVi}=$ mudança no peso vivo;

Prodi= nível de produção (kg de leite ou a lã);

b0= população de interceptação;

b1, b2 e b3= coeficientes de regressão parciais que representam os requisitos de manutenção, requisitos de alimentação para o crescimento, e exigências de alimentação para (re)produção, respectivamente;

ei= termo de erro, o que representa o consumo de ração residual.

Coeficientes de regressão representam o custo médio de manutenção do corpo, crescimento e produção (tal como o número de descendentes), com base na população em que o modelo é formado. Este modelo mostra que o consumo estimado de pastejo se confunde com a eficiência dos recursos alocados. No entanto, quando os animais estão pastando em ambientes pobres em recursos, é mais importante que o animal tenha capacidade de ingerir uma quantidade suficiente de recursos do que se o animal é mais ou menos eficientes na alocação desses (Rauw et al., 2010).

O clima influi indiretamente sobre a produção de lã, através do seu efeito sobre a quantidade e qualidade dos pastos consumidos pelos animais, especialmente para as condições extensivas com alimentação à base de campo nativo, caso do Rio Grande do Sul-Brasil, Uruguai e Argentina (Cardellino, 1983).

Rauw et al. (2010) trabalhando com ovelhas com diferentes graus de sangue Merino Australiano adicionado a um rebanho Merino Rambouillet no deserto de Nevada, ambiente caracterizado por apresentar baixa oferta forrageira, encontraram uma diminuição no diâmetro médio da fibra de lã e seu coeficiente de variação devidamente as limitações ambientais.

Segundo Gea (2007), a maior taxa de crescimento longitudinalmente e diâmetro, se da na primavera e verão, reduzindo no outono para ser mínima no inverno. O crescimento da fibra de lã tem maior resposta a mudanças na alimentação ao decorrer do ano em raças de alta produção, porém raças com grandes capacidades de crescimento de mechas tais como o Cheviot ou Scottish Blackface, mostram pouca ou nenhuma resposta a alterações no status nutritivo durante o inverno (Allden, 1979). Por outra parte, está demonstrado o efeito do fotoperíodo sobre o crescimento da lã. Ciclos sazonais mudam o ritmo anual da taxa de crescimento de lã, quais são controlados pelo fotoperíodo, então, sua alteração é provavelmente um fator importante (Ryder, 2000). Estes efeitos são mediados por meio de secreções hormonais, provavelmente pela glândula pineal. Raças de ovinos, exibindo um grande ritmo anual de crescimento de lã também podem apresentar alterações cíclicas na composição de lã. Assim, Doney e Evans (2000) observaram um ciclo sazonal no teor de enxofre na lã produzida por ovelhas Cheviot alimentadas constantemente com dietas com mesma formulação, em que o teor de enxofre foi mais alto no inverno, quando o crescimento de lã estava em ritmo reduzido. Porém vale ressaltar, embora antiga, porém sem contradição, a afirmação de Nargocka (1979), onde o fotoperíodo, em ovinos da raça Merino, seu efeito direto é escasso ou nulo no crescimento de lã. Abecia et al. (2005) trabalhando com ovelhas das raças Assaf, Aragonesa e Merino Espanhol com o uso melatonina com a hipótese de aumentar o crescimento de lã não encontraram reSultados satisfatório, assim defasando a mesma, onde a melatonina não proporcionou maiores crescimentos.

Ovinos com diâmetro da fibra fino têm uma maior proporção de fibras originadas por folículos secundários e estes folículos não teriam espaço físico para produzir uma variação absoluta do diẩmetro muito marcada diante mudanças nutricionais. Em consequência, as ovelhas que diferem na relação de folículos $\mathrm{S} / \mathrm{P}$ e no diâmetro de fibra, responderiam diferentemente a mudanças no ambiente (Brown e Crook, 2005).

Esse aporte nutricional é determinante no número de folículos, que vai originar o número total de fibras e do tamanho das fibras. Em um ovino adulto ela esta diretamente relacionada com o diâmetro das fibras e o comprimento destas, portanto, com a quantidade e qualidade da lã. Em que animais que passam por um período de baixo consumo, ou até uma subnutrição, geralmente crescem mais rápidos e comem mais durante o período de recuperação, porém esse aumento no consumo não se reflete imediatamente na produção de lã (Heiinzen, 2012).

Por a lã ter um alto conteúdo de aminoácidos Sulfurados, que chega a valores próximos a $14 \%$ dos aminoácidos constituintes, a resposta ao crescimento da lã se associa as quantidades de aminoácidos absorbidos a nível intestinal e por sua vez, o nitrogênio disponível no intestino não está diretamente relacionado com o nitrogênio que contem na dieta, o qual depende de sua degradação e passagem que ocorre a nível ruminal (Heiinzen, 2012). Sabe-se que quando há déficit de enxofre na dieta e, portanto, o conteúdo de cistina no sangue é baixo, os folículos não dispõem de suas exigências dos elementos necessários para formar uma fibra normal, de modo que se forma um cilindro parcial ou totalmente oco (Gea, 2007). A exigência principal é para cistina, mas metionina, que pode ser facilmente convertida em cistina, é igualmente eficaz para estimular o crescimento da fibra de lã. No entanto, quantidades excessivas de metionina são inibitórias (Khan e Qadir, 2008). Um aumento da oferta de cistina para os folículos aumenta a proporção de proteínas de alto teor de enxofre e, portanto, o teor de enxofre da lã. As proporções de proteínas de alta tirosina em lãs também são influenciadas por diversos tratamentos nutricionais, mas nenhum mecanismo de controle foi identificado (Khan et al., 2012).

Andriguetto et al. (2002) descrevem que o uso do enxofre inorgânico, administrado via oral, pode ser utilizado pelos ruminantes para síntese de metionina e cistina. Onde a incorporação de enxofre nas proteí- 
nas, pelos ruminantes, foi demonstrada através do elemento marcado, onde o $S^{35}$ foi transferido para os aminoácidos de leite, lã, sangue e tecidos. Na descrição de experimentos, houve resposta similar tanto ao $S$ dado na forma de metionina, como naquela de Sulfato. $\mathrm{O}$ enxofre elementar mostrou possuir apenas $1 / 3$ da atividade, comparativamente. Os mesmos autores evidenciam a importância dos fenômenos microbianos do trato digestivo na utilização do enxofre inorgânico. A incorporação do enxofre mineral, nas proteínas pelos microrganismos ruminais, parece se ocorrer conforme esquema:

\section{$\mathrm{SO}_{4} \rightarrow \mathrm{SO}_{3} \rightarrow \mathrm{S}_{2} \mathrm{O}_{3} \rightarrow$ Cistina/Cisteína; e ou, Serina $\rightarrow$ Cistina/Cisteína.}

Cistina/Cisteína $\rightarrow$ Proteína; e ou Cistina/Cisteína $\rightarrow$ Homocistina/Homocisteína; e ou Homoserina $\rightarrow$ Homocistina/Homocisteína.

\section{Homocistina/Homocisteína $\rightarrow$ Metionina $\rightarrow$} Proteína.

Os efeitos de minerais parecem ser devido a mudanças no fornecimento de nutrientes principais provocado pelas mudanças no consumo de ração ou no equilíbrio de nutrientes que flui no rúmen. Efeitos específicos no crescimento de fibras apenas são demonstrados por zinco e cobre, e mesmo alguns destes podem estar relacionados a alterações no consumo de ração. Deficiência de zinco em ovinos provoca lã quebradiça e perda das ondulações. A deficiência extrema faz com que ocorra estagnação no crescimento da fibra e perda de qualidade do velo (Khan et al., 2012). Deficiência de cobre causa despigmentação da lã em ovinos naturalmente coloridos, e afeta a qualidade pela síndrome da lã de aço. Suplementação de cobre especificamente pode estimular o crescimento de lã (Purser, 2000).

Abella (2007) trabalhou com ovinos da raça Merino Australiano, mantidos em manejo a pasto em três sistemas. Em que o pastoreio contínuo teve uma produção de matéria seca (MS) de $157 \mathrm{~kg}$ no primeiro ano e no segundo $1220 \mathrm{~kg}$ e os manejos com pastoreio rotativo intensivo em média apresentaram $313 \mathrm{~kg}$ de MS e $2071,5 \mathrm{~kg}$ de MS no primeiro e segundo ano, respectivamente. Assim o autor obteve maiores valores de pesos de velo sujo e limpo, maior diâmetro médio, maior resistência da fibra e maior comprimento de mecha para os animais manejados em campo nativo.

A esquila pode ter efeitos positivos na qualidade da lã quando aplicada em momentos estratégicos. Sacchero e Mueller (2007) observaram que lãs oriundas de esquila pré-parto, as fibras apresentaram ponto de diâmetro mínimo próximo aos extremos da mecha, devidamente por estarem passando por momentos de menor oferta forrageira e aumento das exigências nutricionais (gestação e lactação), e observaram que o ponto de maior diâmetro coincidiu com períodos de maior oferta forrageira e menores exigências nutricionais. Outro aspecto a ser considerado é a exposição da ponta da mecha a condições de radiação solar, vento, chuva, variações de temperatura e umidade (quando o ponto de diâmetro mínimo é muito próximo à ponta), podem afetar a descamação da cutícula das fibras, logo diminuindo o diâmetro (Sacchero et al., 2010).

Silveira et al. (2014b) trabalhando com 26 cordeiros da raça Corriedale, em que a metade foi esquilada e a outra não, encontram que nos que foram submetidos a esquila apresentaram um maior crescimento de mecha nos primeiros três meses pós a data da esquila.

Outro ponto importante na de produção de lã é a sanidade, pois a falta dela pode reduzir substancialmente o crescimento da lã (Khan et al., 2010), particularmente em ovinos infectados pela primeira vez por endoparasitas, onde sua resistência está se desenvolvendo, e também em ovelhas gestantes e parindo. Nestas situações há um prejuízo maior na produção lanosa (Gea, 2007). Assim Silveira (2014) trabalhando com 32 cordeiras da raça Corriedale, onde acompanhou seus níveis de infecção por nematoides dos três meses de idade até um ano de vida para caracterizar animais com susceptibilidade ou resistência. Todavia não encontrou diferença no comprimento nem no crescimento de lã entre animais de baixa, média e alta infecção.

Na província de Rio Negro, Argentina Sacchero et al. (2010) trabalhando com duas linhas genéticas de Merino, uma selecionada para diâmetros de fibra superfina e outra sem seleção, em dois anos climaticamente diferentes, o primeiro com pluviosidade anual de $350 \mathrm{~mm}^{3}$ e o segundo com $213 \mathrm{~mm}^{3}$, obtiveram diferença no diâmetro médio das fibras de 2,7 micras a menos para os animais da linha superfina, onde afirmam que esse resultado deve-se a introdução de germoplasma superfino australiano e a maior ênfase em seleção por animais com características superfina. Outro ponto que mostra a importância da seleção é a baixa variação do diâmetro em diferentes condições climáticas, em que os animais sem seleção passaram de 20,7 para 19,6 micras e o grupo selecionado de 17,9 para 17,4 micras entre os períodos maior e menor precipitação, respectivamente.

Outro ponto de importância tecnológica, porém sem direta aplicação pratica é a região corporal, onde Amarilho-Silveira e Lemes (2014) em trabalho com ovelhas Corriedale, encontraram melhores qualidades de lã na região da paleta, logo sendo a coxa ostentadora de piores fibras. Quais fatores são de atribuição genética, e de baixa influência ambiental (Amarilho-Silveira e Lemes, 2014).

Há algumas ferramentas que não são fatores de produção, porém são estimativas de futuras respostas, onde com a atribuição de valores de repetibilidade (R) e herdabilidade $\left(\mathrm{h}^{2}\right)$, podemos iniciar e/ou otimizar processos de seleção. Neste sentido Gimeno e Preve (2011), analisaram 1229 dados de grau de amarelamento (Y-Z) e 750 de diâmetro (DF), de fêmeas da raça Corriedale nascidas em diferentes anos. Para o DF encontraram alta $h^{2}$ e $R(0,68$ e 0,73, respectivamente), e para o Y-Z encontraram valores altos de $h^{2}(0,37)$ e médios de $\mathrm{R}(0,41)$. Rauw et al. (2010) encontraram estimativas de herdabilidade médias a altas $(0,51)$ para característica de diâmetro de fibra e correlações genéticas e fenotípicas entre diâmetro de fibra e coeficiente de variação do diâmetro de 0,49 e 0,14, respectivamente. 


\section{CONSIDERAÇÕES FINAIS}

O entendimento das características e da produção de lã são fatores limitantes na atividade, pois apesar de ser um produto tratado como coproduto da ovinocultura, na maioria dos países que desenvolve essa atividade, ele apresenta características que não existe em mais nenhum produto.

Em vista de ser biodegradável onde sua produção é de maneira sustentável, cria-se uma demanda contrapondo principalmente as fibras derivadas do petróleo, pois estas além de serem de fontes esgotáveis apresentam grande impacto no ambiente. Com isso fortalece, e prospecta-se uma maior demanda mundial pela lã, qual supre os requisitos de beleza, conforto e ecológico.

Outro ponto, talvez o principal, é que esse material foi elaborado devido à escassez de informações, reunidas, concernente à produção de lã. Onde na grande maioria das bibliografias, se não são replicações de trabalhos muito antigos, são os próprios. Atualmente, mesmo sendo o cordeiro o produto nobre ovino, a lã é passível de ganhos econômicos principalmente em raças de duplo propósito, que é o que acontece em países como Uruguai, Argentina e Nova Zelândia. Os mesmos como grandes ovinocultores, ostentando números, expressivos, nas exportações no mercado internacional da carne ovina. E que, raças como a Corriedale e a Romney Marsh apresentam grande participação no sistema.

\section{BIBLIOGRAFIA}

Abecia, J.A.; Valares, J.A. and Forcada, F. 2005. The effect of melatonin treatment on wool growth and thyroxine secretion in sheep. Small Rumin Res, 56: 265-270.

Abella, I. 2007. Efecto del sistema de pastoreo y de la suplementación proteica sobre la producción de lana de ovejas Merino. Producción Ovina, 19: 59-69.

Agricultural Research Council-ARC. 1980. The nutrient requirements of ruminant livestock. Commonwealth Agricultural Bureaux. London. $351 \mathrm{pp}$.

Agricultural and Food Research Council-AFRC. 1993. Energy and protein requirements of ruminants. An advisory manual prepared by the AFRCT Technical Committee on responses to nutrients. CAB International. Wallingford. UK. $151 \mathrm{pp}$.

Allden, W.G. 1979. Feed intake, diet composition and wool growth. In: J.L. Black; P.J. Reis (Eds.). Physiological and environmental limitations to wool growth. The University of New England Publishing Unit. Armidale, NSW. pp. 61-78.

Amarilho-Silveira, F. e Lemes, J.S. 2014. Qualidade da lã em diferentes regiões do velo de ovelhas da raça Corriedale. IN: V Congreso de la Asociación Uruguaya de Producción Animal. Facultad de Agronomía, Montevideo.

Andriguetta, J.M. 2002. Nutrição animal. Bases e os fundamentos da nutrição animal. Os alimentos. v. 1. Editora Nobel. São Paulo. 387 pp.

Barzola, J.C.G. 2009. Evaluación del método de clasificación del vellón de ovino Corriedale (Ovis aries) en la S.A.I.S Pachacutec. Tese. Universidad Nacional Agraria la Molina. Perú. 67 pp.

Brown, D.J.; Crook, B.J. and Purvis, I.W. 2002. Differences in fibre diameter profile characteristics in wool staples from Merino sheep and their relationship with staple strength between years, environments and bloodlines. Aust J Agr Res, 53: 481-491.

Brown, D.J. and Crook, Y.B.J. 2005. Environmental responsiveness of fibre diameter in grazing fine wool Merino sheep. Aust J Agr Res, 56: 673-784
Bottaro, M.P. 2013. La lana en un nuevo escenario para las materias primas. Lana Noticias, 165: 26-27.

Bottaro, M.P. 2014. Mercado de lana. Lana Noticias, 168: 12-14.

Cardellino, R. 1983. Importancia de las características de la lana. Secretariado Uruguayo de la Lana. Ovinos y Lanas, n. 10.

CSIC BIO022. 2008. Consejo Superior de Investigaciones Científicas. Lipideos internos de la lana en la preparación de produtos para el tratamiento y cuidado de la piel. http://www.ott.csic.es/ (27/01/2015).

CSIC BIO023. 2008. Consejo Superior de Investigaciones Científicas. Ceramidas de la lanlolina para el tratamiento de la piel. http://www. ott.csic.es/ (27/01/2015).

Doney, J.M. and Evans, C.C. 2000. The influence of season and nutrition on the sulphur content of wool from Merino and Cheviot sheep. J Agr Sci, 70: 111-116.

Friends, M.A. and Robards, G.E. 2005. Fibre diameter and staple strength of sheep selected for divergent clean fleece weight when subjected to an increase in intake or an increase in intake and diet change. Aust J Agr Res, 56: 195-201.

Gea, G. 2007. Ganado lanar. El ganado lanar en la Argentina. $2^{a}$ ed. Universidad Nacional de Río Cuarto. Río Cuarto. Córdoba. 280 pp. Gimeno, D. y Preve, F. 2011 . Repetibilidad del diámetro promedio de la fibra y grado de amarillamiento de la lana en hembras Corriedale. Producción Ovina, 21: 49- 53.

El Pais. 2013. China compró lanas y movió el mercado local. Jornal El Pais. Rurales. Montevideo. 28 de setembro de 2013.

Hearle, J.W.S. 2005. A total model for stress-strain of wool and hair. Proc $11^{\mathrm{th}}$ Int. Wool Text. Res. Conf. Leeds, 66: 1-10.

Heiinzen, M. 2012. Alimentación y producción de lana. CuencaRural. com. http://www.cuencarural.com/ganaderia/ovinos/79280alimentacion-y-produccion-de-lana/ (26/03/2014).

International Wool Textile Organization - Iwto. 2013. http://www.Iwto. org/wool/history-of-wool/ (30/05/2013).

Khan, M.J. and Qadir, S. 2008. Nutritive value and digestion kinetics of manure ensiled wheat straws treated with varing levels of urea and corn grains. J App/ Sci Environ Manage, 12: 103-106.

Khan, M.J.; Basit, A. and Arshad, H.M. 2010. Epidimiological studies on different factors affecting growth performance of animals in Southern Punjab. National conference on the stratigies to improve red meat production in Pakistan. p. 36.

Khan, M.J.; Abbas, A.; Ayaz, M.; Naeem, M.; Akhter, M.S and Soomro, M.H. 2012. Factors affecting wool quality and quantity in sheep. Afr J Biotech, 73: 13761-13766.

Lee, G.J.; Atkins, K.D. and Swan, A.A. 2002. Pasture intake and digestibility by young and non-breeding adult sheep: The extent of genetic variation and relationships with productivity. Livest Prod Sci, 73: 185-198.

Martincorena, J. 2013. Congreso Anual Iwto, Biella, Italia. Lana Noticias, 165: 20-21.

McGregor, B.A. 2012. Properties, processing and performance of rare and natural fibres: a review and interpretation of existing research results. Rural Industries Research and Development Corporation. Australian Goverment. Publication 11/150. 103 pp.

Minola, J. y Elissondo, A. 1990. Praderas y lanares - Tecnologia ovina sudamericana. Editora Hemisfério Sur. Buenos Aires. v. 1, p. 64.

Minola, J. y Goyenechea, J. 1975. Praderas e lanares. Produción ovina en alto nivel. Editora Hemisfério Sur. Montevideo, Uruguay. 64 pp.

Naebe, M. 2009. Effect of plasma on the properties of protein fibres. Ph.D. Thesis. Deakin University. Geelong. Victoria. Australia.

Nagorcka, B.N. 1979. The effect of photoperiod on wool growth. In: Black, J.L and Reis P.J., Eds. Physiological and environmental limitations to wool growth. University of New England Publishing Unit. pp. 127-137.

National Research Council-NRC. 1985. Subcommittee on Sheep Nutrition, Washington D.C. Nutrient Requeriments of Sheep. 5th ed. National Academy of Science. Washington. 71 pp.

National Research Council - NRC 2007. Nutrient requeriments of small ruminants. 1 st ed. National Academy Press. Washington, DC. USA. $362 \mathrm{pp}$. 
Nocchi, E.D.G. 2001. Os efeitos da crise da lã no mercado internacional e os impactos sócio-econômicos no município de Santana do Livramento, RS. Brasil. 2001. 87 f. Dissertação (Mestrado em integração e cooperação internacional). Universidad Nacional de Rosario.

Osório, J.C.S. 1979. Efeitos ambientais e correlação entre componentes do peso de velo em ovelhas da raça Ideal, 1979. 83 f. Dissertação (Mestrado em produção animal). Departamento de Zootecnia. Universidade Federal do Rio Grande do Sul.

Osório, J.C.S. e Osório, M.T.M. 2004. Lã. In: Osório, J.C.S. e Osório, M.T.M. Zootecnia de ovinos: Raças, lã, morfologia, avaliação de carcaças, comportamento em pastejo. Departamento de Zootecnia. Faculdade de Agronomia Eliseu Maciel. Universidade Federal de Pelotas. Pelotas. 123 pp.

Osório, J.C.S.; Osório, M.T.M.; Vargas Junior, F.M. e Leão, A.G. 2014 Produção e qualidade de lã. In: Selaive, A. B. e Osório, J.C.S. Produção de ovinos no Brasil. Roca, Vila Mariana, Brasil. 29: 449-467.

Purser, D.B. 2000. Effects of minerals upon wool growth. University of New England Publishing Unit. Armidale. pp. 243-255.

Rauw, W.M. 2008. Introduction. In: Resource allocation theory applied to farm animal production. CABI Publ. Wallingford. UK. pp. 1-21.

Rauw, W.M.; Thain, D.S.; Teglas, M.B.; Wuliii, T.; Sandstrom, M.A. and Gomez-Raya, L. 2010. Adaptability of pregnant Merino ewes to the cold desert climate in Nevada. J Anim Sci, 88: 860-870.

Ryder, M.L. 2000. Coat structure and seasonal shedding in goats. Anim Prod, 8: 289-302

Sacchero, D. y Mueller, J.P. 2007. Diferencias en el perfil de diámetro de fibras, largo de mecha y resistencia a la tracción de la lana en ovejas de una majada Merino seleccionada y una no seleccionada. Rev Invest Agropecuarias, 36: 49-61.

Sacchero, D.; Willems, P. y Mueller J.P. 2010. Perfiles de diámetro de fibra en lanas preparto de ovejas merino. 1. Estudio comparativo de líneas genéticas. Rev Argent Prod Anim, 30: 31-42.

Sacchero, D.; Willems, P. y Mueller J.P. 2011. Perfiles de diámetro de fibra en lanas preparto de ovejas merino. 2. Estudio comparativo de estados fisiológicos. Rev Argent Prod Anim, 31: 39-50.

Silveira, H.S. 2005. A Coordenação na cadeia produtiva da ovinocultura como instrumento para o desenvolvimento regional: $\mathrm{O}$ caso da iniciativa local do Cordeiro Herval premium. Dissertação (Mestrado em Agronegócios). Universidade Federal do Rio Grande do Sul, f. 104.

Silveira, F.A. 2014. Contagem de ovos por grama de fezes (OPG) e produtividade de cordeiras Corriedale como expressão da resistência a nematoides. 2014. $33 \mathrm{f}$. Trabalho de conclusão de curso - Curso de Zootecnia. Universidade Federal de Pelotas. Pelotas.

Silveira, F.A.; Lemes, J.S. e Ferreira, O.G.L. 2014a. Qualidade da lã em diferentes regiões corporais de ovelhas da raça Corriedale. In: XXIII Congresso de Iniciação Científica da Universidade Federal de Pelotas. Anais... Pelotas.

Silveira, F.A.; Silveira, R.F.; Kröning, A.B.; Lemes, J.S.; Farias, P.P. e Ferreira, O.G.L. 2014b. Influência da esquila no desempenho de cordeiros da raça Corriedale. In: VISimpósio Brasileiro de Agropecuária Sustentável e III Congresso Internacional de Agropecuária Sustentável. Anais... Universidade Federal de Viçosa. Viçosa.

Schinckel, P.G. e Short, B.F. 2001. The influence of nutritional level during pre-natal and early post-natal life on adult fleece and body characters. Aust J Agr Res, 12: 176-202.

Sul. Secretariado Uruguayo de la Lana. 1987. Apuntes de lanares y lanas. Razas. Mejoramiento ovino. Sección Extensión. 129 pp.

Thompson, A.N. and Young, J.M. 2002. Potential economic benefits from improving ewe nutrition to optimize lifetime wool production and quality in southwest Victoria. Proc. Wool Industry Science e Tecnology Conference. Hamilton, Victoria. Australia.

Tung, W.S. e Daoud, W.A. 2009. Photocatalytic self-cleaning keratins: A feasibility study. Acta Biomater, 5: 50-56.

Viana, J.G.A. 2008. Governança da cadeia produtiva da ovinocultura no Rio Grande do Sul: estudo de caso à luz dos custos de transação e produção. 137 f. Dissertação (Mestrado em Extensão Rural). Faculdade de Zootecnia. Universidade Federal de Santa Maria.

Vieira, G.V.N. 1967. Criação de ovinos. $3^{a}$ edição. Edições Melhoramento. Porto Alegre. 480 pp.

Vílchez Maldonado, S. 2005. Nuevos tratamientos de lana con enzimas. Facultad de Química. Universidad de Barcelona. 44 pp.

Wallace, A.L.C. 2000. The effect of hormones on wool growth. University of New England Publishing Unit. Armidale. pp. 257-268.

Williams, A.J. and Butt, L. 1989. Wool growth of pregnant Merino ewes fed to maintain maternal live weight. Aust J Exp Agr, 29: 503-507. 